\title{
A importância dos provérbios no Judeu-Espanhol
}

Aléxia Teles Guimarães**

RESUMO: Divulgação da existência da cultura e língua dos judeus sefarditas orientais, através da verificação da importância dos provérbios escritos em judeu-espanhol.

Os 500 anos da expulsão dos judeus da Espanha em 1492 têm estimulado estudiosos a interessarem-se pela língua e cultura dos judeus sefarditas. No entanto, a difusão destes trabalhos é muito restrita e muitos desconhecem esta cultura. O que é o judeu-espanhol? E os sefarditas? Por que a importância dos provérbios? Este trabalho consiste numa apresentação de estudos feitos por HARRIS e KOEN-SARANO sobre o judeu-espanhol e seus falantes.'

Os provérbios judeu-espanhóis são o espelho do grupo étnico judeu-espanhol, se observarmos a língua em que se apresentam e o seu conteúdo moral e cultural.

Em 1492, os judeus espanhóis que não se converteram ao catolicismo foram expulsos da Espanha pelo rei Fernando e pela rainha Isabela. Estima-se

* Recebido para publicação em agosto de 1996.

:k Aluna de graduação da Faculdade de Letras da UFMG. Graduada em francês pela FALE-UFMG. Bolsista do PIBIC-CNPq.

1 A bibliografia citada ajudará inclusive a conceber umá pesquisa sociolinguística do judeu-espanhol na cidade de Belo Horizonte, sob a orientaçāo da Profa. Dra. Maria Antonieta Cohen, com patrocínio do PIBIC-CNPq. 
que entre 100.000 e 175.000 deles foram forçados a se exilar. São estes exilados os judeus sefarditas, palavra de origem hebraica onde "sepharad" significa "Espanha". Os judeus sefarditas conheciam o espanhol datado do fim do século XV e início do século XVI. Foram três as principais rotas seguidas por eles (HARRIS 1994):

- África do Norte, especificamente norte do Marrocos. Sua língua é uma mistura de espanhol e árabe, sendo chamada de "hakitia";

- Portugal, sendo expulsos dali em 1497 e partindo então para outros países europeus (Holanda, França, Inglaterra, Alemanha, etc.). São os chamados sefarditas ocidentais que continuaram em contato com a Espanha e Portugal. Acabaram tomando como língua a falada no país em que viviam;

- Império Otomano que compreende atualmente Grécia, Turquia, ex-Iugoslávia, Bulgária, Romênia e Israel. Estes são os chamados sefarditas orientais, que perderam todo e qualquer contato com as culturas e línguas ibéricas, não sendo expostos consequientemente às suas influências linguiísticas. A língua dos sefarditas orientais preservou várias das características do espanhol arcaico. Além disso, esta língua sofreu várias formações e transformações independentes, outro reflexo do isolamento lingüístico em relação à Península Ibérica. Por ser uma língua falada por judeus, recebeu empréstimos do hebreu e era escrita nos caracteres desta língua ou em "rashi". Ao longo dos anos, o espanhol dos sefarditas orientais adquiriu uma importante quantidade de empréstimos e de elementos estrangeiros do turco, grego, italiano e francês. Nasceu assim o judeu-espanhol.

A língua dos sefarditas orientais recebe vários outros nomes além do judeu-espanhol, tais como ladino e judezmo, gerando este fato bastante controvérsia no meio acadêmico, mas não cabe aqui no momento refletir sobre este aspecto.

Atualmente o judeu-espanhol é falado basicamente por idosos e seu número de falantes está em decréscimo, incitando-nos mais ainda a estudá-lo, sob todos os aspectos. Os provérbios no judeu-espanhol possuem acentuada importância para os próprios sefarditas e são eles mesmos que confirmam tal idéia:

- Refran(iko) mentiroso no hay. / Não existe provérbio que minta.

- En tus apuros I afanes, toma konsezo de los refranes. / Na hora dos apuros e dificuldades, siga o conselho dos provérbios. 
KOEN-SARANO (1995) afirma que os provérbios judeu-espanhóis não só descrevem uma situação ou a criticam, para exercer uma influência sobre ela e mudá-la, como também têm um significado mais amplo: "não somente uma frase, mas uma palavra só, uma expressão verbal, uma interjeição (...) tem a autoridade da tradição, (...) repetindo-se no discurso para obter um efeito particular e para dar mais peso às palavras ditas (...)". ${ }^{3}$

O assunto mais comum dos provérbios judeu-espanhóis é a maneira de ser do judeu sob seu próprio ponto de vista em geral. Além disso, apresenta uma função educativa importante ao criticar até mesmo ironicamente ou sarcasticamente pessoas e atitudes. Nunca se ressalta o fato de que o judeu do qual está se falando seja particularmente sefardita oriental, mas esta idéia pode ser confirmada ao observarmos a língua em que foi escrito o provérbio e o local em que foi encontrado. Vejamos alguns aspectos sócio-culturais interessantes retratados pelos provérbios:

- A inteligência dos judeus:

Djidio bovo no ay. / Não existe judeu bobo.

Dijdio savi lo ke otros no tienin ni la idea. / O judeu sabe o que os outros não fazem nem idéia.

El judiyo kuadro kevra si vienta asa. / Quando o judeu erra, aprende com o seu erro.

- A solidariedade entre os judeus:

Djudio ki no ayuda a outro djudio no ai. / Não existe judeu que não ajude outro judeu.

Ken es el enemigo del Djudio? Otro djudio, ma no en la ora di angustia. / Quem é inimigo do judeu? Um outro judeu, mas não na hora da angústia.

- O gosto pelo dinheiro:

Kuando se enrekese un Djudio la muyer se le vee fea I la caza estrecha. I Quando um judeu fica rico, sua mulher se torna feia e sua casa pequena. Espantate de Djudio riko, de Grego borachi I de Turko prove. / Cuidado com judeu rico, grego bêbado e turco pobre.

Gana Komo el Djudio I gasta como el kristiano. / Ganha (dinheiro) como um judeu e gasta como um cristão.

3 Traduzido do judeu-espanhol.

CALIGRAMA - Belo Horizonte, 2:97-101 - novembro/1997 
- A relação entre judeus e turcos:

Mas vale murir Djidio I no murir turco. / É melhor morrer judeu do que não morrer turco.

- O estigma de sofrimento eterno dos judeus:

El Djudio es de vidro. Si aharva la piedra al vidro: guay del vidro; I si aharva el vidro a la piedra, quay del vidro./ Os judeus têm culpa de tudo: a culpa é deles se eles fizeram algo e também se não o fizeram. En este mundo sufrimos porke somos Djudios. En el otro sufriremos porke no fuemos Djudios. / Sofremos neste mundo porque somos judeus; no outro sofreremos porque não fomos judeus.

- A importância dada à família:

La madre es madre, I lo demas es aire. / Mãe é mãe, o resto é resto. Ken no tiene iza, no tiene amiga. / Quem não tem filha não tem amiga. Izos de mi izos, dos vezes mi izos./ Filhos dos meus filhos, duas vezes meus filhos.

- O humor:

El haham por onde kere bolta la oshika. / Quando o rabino não sabe responder uma pergunta, vira a página e fala de outras coisas.

Suegra ni de barro es buena. / Sogra nem de barro é boa.

El gameyo no ve sur korkova, ve la de su vizino. / O camelo não vê sua própria corcova, mas a do vizinho sim.

GOLDBERG (1993, apud HARRIS, 1994) enfatiza que os provérbios em si também passam por transformações: "Assim como um dialeto experimenta mudanças fonológicas, morfológicas, sintáticas e lexicais, o discurso dos seus falantes também sofre transformações: a memória coletiva perde algumas legendas e provérbios, novas histórias criam novos dizeres; algumas máximas mudam de contexto e outras parecem ganhar significados adicionais."

As pesquisas sobre os provérbios em judeu-espanhol são várias, isto porque sua riqueza lingüística e cultural é significativa e inquestionável. Se tomamos como corpus estes provérbios, percebemos a essência do mundo judeuespanhol na sua totalidade e sob vários aspectos mais específicos, tais como

4 Traduzido do inglês. 
família, amor, dinheiro, saúde, doença, morte, casamento, felicidade... Os provérbios não só indicam uma preocupação com a autoridade da tradição e do bom senso que vão passando de geração em geração, como dão pistas relevantes sobre seus falantes e falares.

RÉSUMÉ: Divulgation de l'existence de la culture et de la langue des juifs sefardis orientaux à travers la vérification de l'importance des dictons écrits en judeo-espagnol.

\section{REFERÊNCIAS BIBLIOGRÁFICAS}

HARRIS, Tracy K. Death of a language: the history of Judeo-spanish.Cranbury: Associate University Press, 1994.

KOEN-SARANO, Matilda. Temas djudios en el reflan djudeo-espanyol. Los muestros. Bruxelas, n.21, p.44-50, dezembro 1995. 